\title{
Effect of Large Scale Wind Farms On the Egyptian Power System Dynamics
}

\author{
M. El-SAYED ${ }^{1}$, Effat MOUSSA ${ }^{2}$ \\ ${ }^{1}$ Electrical Power Engineering . Dept., \\ Cairo University \\ Phone number:(+202)35832195, e-mail: elsmah@hotmail.com \\ 2-Egyptian Electricity Holding Company \\ Phone number (202)24832437 / fax (+202)24011630 \\ e-mail: effat_moussa@hotmail.com
}

\begin{abstract}
In recent years wind energy has become an important source of clean electrical generation. Therefore, the penetration of wind turbines in electrical power systems will be increasing and then they may begin to influence overall power system behavior, making it impossible to run a power system by only controlling large scale power plant $[1,2]$. This foreseen expansion will result in many technical issues which must be dealt with in order to guarantee that the quality of the utility power is not affected.

In this paper aggregated wind farm modeling is presented to investigate the effect of wind farms of different sizes on the Egyptian power system dynamics. The wind farm is aggregated into minimal set of equivalent wind generator models combining all turbines with the same mechanical nature frequency into single equivalent turbine. Power system dynamics simulation software is used to study the impact of increasing wind turbine penetration on system performance. The proposed technique presented in [1] is applied to estimate the reduction in conventional electric capacity in presence of Wind Turbine Generators is applied while selecting the proposed wind farm size. The result shows that the Egyptian system can withstands wind farms of size up to 900 MW.
\end{abstract}

\section{Keywords}

Wind turbine, Power system Dynamic, Aggregated modeling, Power reserve

\section{INTRODUCTION}

Recently, wind energy development has experienced a significant level of interest as clean source of Electrical generation. The rise in the use of wind generators is accompanied by a need to evaluate their impact on power system dynamics for electrical power system planning. Because large wind installations consist of many wind generators, representative wind park modeling is a critical need. Consequently, the first goal of this paper is to investigate the effect of wind farms of large sizes on the power system dynamics by combining several wind turbines with the same mechanical nature into single equivalent turbine connected to the transmission system through a single bus $[3,4]$. The second goal is to estimate required system reserve after adding such large wind farms in replacement of conventional generating units to maintain the same pre-specified system reliability levels as before introducing such wind farms.

\section{AGGREGATION METHODOLOGY}

The premise for the proposed approach is the following: because the turbines are all tied to a common bus, each turbine within the park is subject to the same disturbance torque. Therefore, turbines of similar properties will oscillate in phase with each other, and the turbines can be combined as a mechanical parallel combination [3,5]. For example consider the case of $n$ turbines of the same natural frequency is to be combined, then:

$$
\mathrm{J}=\sum_{\mathrm{i}=1}^{\mathrm{n}} \mathrm{J}_{\mathrm{i}} \quad, \quad \mathrm{K}=\sum_{\mathrm{i}=1}^{\mathrm{n}} \mathrm{K}_{\mathrm{i}}, \quad \mathrm{D}=\sum_{\mathrm{i}=1}^{\mathrm{n}} \mathrm{D}_{\mathrm{i}}
$$

Where:

$\mathrm{J}_{\mathrm{i}}, \mathrm{K}_{\mathrm{i}}, \mathrm{D}_{\mathrm{i}}$ are the inertia , spring and damping terms for the turbine i.

\section{Electrical Power}

The fundamental criterion of the assumed equivalence is that the active power absorbed by all the $n$ individual unit

$$
\mathrm{P}=\sum_{\mathrm{i}=1}^{\mathrm{n}} \mathrm{P}_{\mathrm{i}}
$$

The same formula is also valid for the reactive power [4].

\section{Aggregated Model impedance}

Defining $\mathrm{Z}_{\mathrm{s}}=\mathrm{R}_{\mathrm{s}}+\mathrm{j} \mathrm{X}_{\mathrm{s}} \quad$ as a stator impedance, $\mathrm{Z}_{\mathrm{r}}=\mathrm{R}_{\mathrm{r}}+\mathrm{j} \mathrm{X}_{\mathrm{r}}$ as a rotor impedance at blocked rotor condition ( $\mathrm{s}=1)$. 
$\mathrm{Z}_{\mathrm{m}}=\mathrm{j} \mathrm{X}_{\mathrm{m}} \quad$ is the magnetizing impedance. The equivalent circuit can be expressed as shown in figure (1).

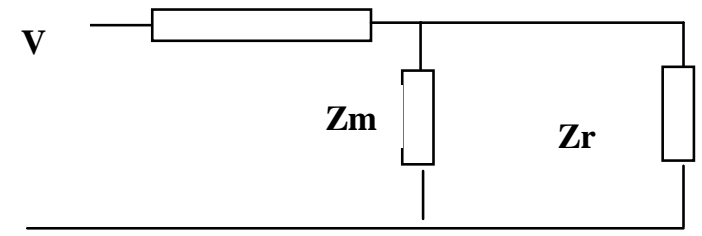

(a)

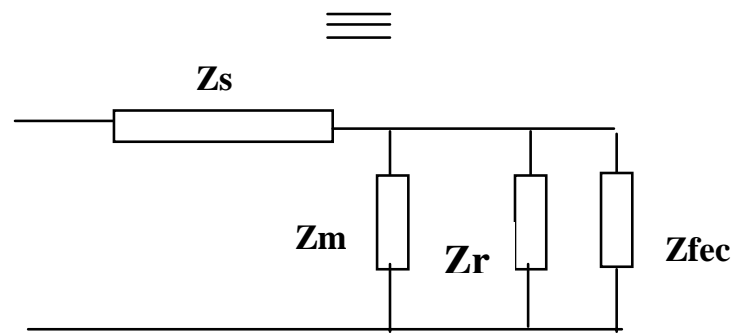

(b)

Fig. (1) (a) Usual equivalent circuit (b) Alternative equivalent circuit

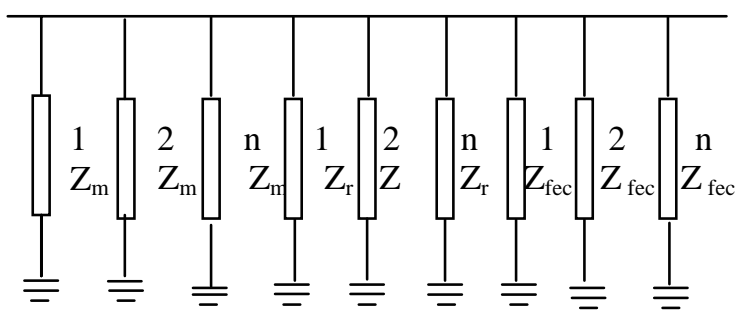

Fig. (2) Grouping the induction machines

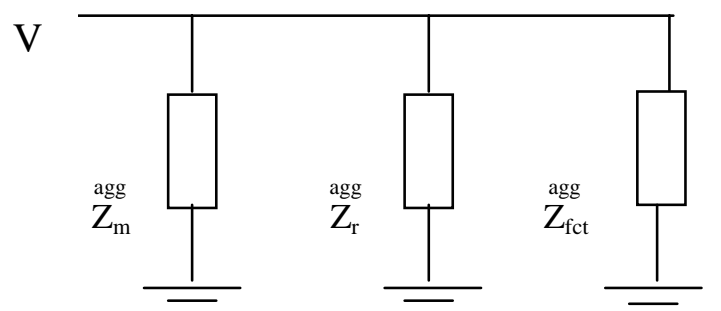

(a)

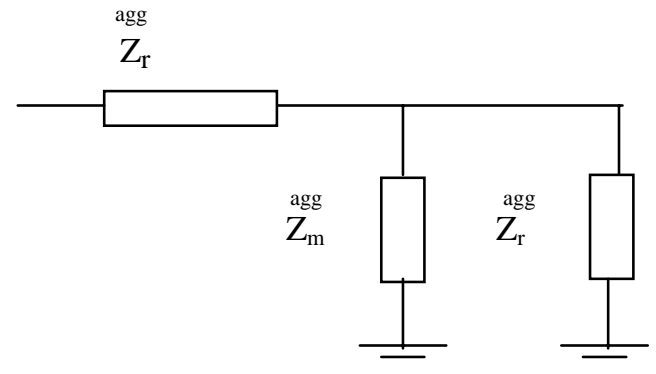

Fig.(3) The aggregated induction machine model
Where, $\mathrm{Z}_{\mathrm{fec}}$ represents fictitious impedance whose role is only to guarantee that both models are equivalent, i.e same voltage and same current [4]. Since the two models should be equivalent, then $\mathrm{Z}_{\mathrm{fec}}$ can be obtained from:

$$
\mathrm{Z}_{\mathrm{s}}+\frac{1}{\frac{1}{\mathrm{Z}_{\mathrm{m}}}+\frac{1}{\mathrm{Z}_{\mathrm{r}}}}=\frac{1}{\frac{1}{\mathrm{Z}_{\mathrm{m}}}+\frac{1}{\mathrm{Z}_{\mathrm{r}}}+\frac{1}{\mathrm{Z}_{\text {fec }}}}
$$

For aggregating $\mathrm{n}$ machines connected at the same bus, let that they are represented by the three impedances in parallel model. They can be grouped as shown in figure (2). Consequently, the aggregate equivalent circuit model defined in figure 3(a) where:

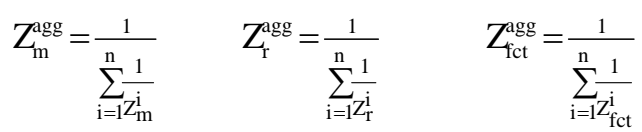

The final equivalent circuit model of the aggregate induction generator can be given as in figure 3(b):

Where:

$$
Z_{\mathrm{s}}^{\mathrm{agg}}=\frac{\mathrm{Z}_{\mathrm{m}}^{\mathrm{agg}} \mathrm{Z}_{\mathrm{r}}^{\mathrm{agg}}}{\mathrm{Z}_{\mathrm{m}}^{\mathrm{agg}}+\mathrm{Z}_{\mathrm{r}}^{\mathrm{agg}}}\left[\frac{\mathrm{Z}_{\mathrm{fct}}^{\mathrm{agg}}\left(\mathrm{Z}_{\mathrm{m}}^{\mathrm{agg}}+\mathrm{Z}_{\mathrm{r}}^{\mathrm{agg}}\right)}{\mathrm{Z}_{\mathrm{fct}}^{\mathrm{agg}}\left(\mathrm{Z}_{\mathrm{m}}^{\mathrm{agg}}+\mathrm{Z}_{\mathrm{r}}^{\mathrm{agg}}\right)+\mathrm{Z}_{\mathrm{m}}^{\mathrm{agg}} \mathrm{Z}_{\mathrm{r}}^{\mathrm{agg}}}-1\right]
$$

\section{SYSTEM OPERATION CONSTRAINTS}

The basic power system security constraints for acceptable system operation, which are considered within the proposed approach could be summarized as [1]:

-Line flow constraints,

-Load constraints

-Voltage magnitude limits

-System frequency limits

The system reliable operation is modeled by an optimal based load flow with an objective function:

$$
\text { Minimize } \quad L S D=\sum_{i} L_{i}
$$

Where, $\mathrm{LSD}_{\mathrm{i}}$ is the amount of a load that has to be shed due to system disturbance according to the load shedding scheme at designated bus i to maintain secure system operation.

The occurrence of system emergency conditions may, by itself, be recorded as a failure event. However, it is possible to eliminate system problem(s) by taking appropriate corrective action(s) without load shedding. These corrective actions are simulated through rescheduling generators active power to overcome line overloading or rescheduling reactive power to correct voltage violation at controlled buses; they are treated as the optimal function formulation control variables. On the other hand, load buses voltage violation may be adjusted by switching 
reactive power compensation units (reactors or capacitor banks) at load buses; they are used as control variables.

\section{SYSTEM CONTENGENCY ANALYSIS}

\section{Transmission line outages}

A deterministic contingency analysis procedure was used to select the outage states that violate system operation limits for up to two simultaneous circuits. Later a detailed analysis was done using a detailed AC load flow program.

\section{Loss of Generation Units}

Sudden loss of large units causes noticeable drop in the average frequency of electric power systems. Severe transient frequency drop for few seconds may endanger the overall stability of the system. In order to let the system return to its nominal frequency some of the loads must be shed. The load is shed in steps according to the value of the system frequency; this allows the time required for the generation reserve to pick-up part of the load. The frequency is closely related to the real power balance in the overall system so that the rate of change of stored kinetic energy at any instant is equal to the difference between power input to the system and power output [6]. In this paper generating unit outages were done for single unit and up to four simultaneous units.

\section{Loss of Generating Unit and Transmission line}

Failure-effect analyses were carried out to define the generation-transmission combination outages in the same vicinity, which violate the overall system operation constraints.

\section{SYSTEM MODELING}

\section{The Generating Units}

The system under study is composed of different generation units at specific locations with various capacity limits, availability and type as follows: Steam units, GT's, Combined cycle, hydro and WTGs. The modeling of each type of units incorporates specific restrictions of their operation .

\section{The transmission lines}

The transmission lines are modeled by their thermal limits, line availability and its impedance as well as admittance as function of line length.

\section{The Load.}

At each bus specific energy and power demand would be supplied under the form of load curve. When chronology of the load is not important, the hourly loads are often modeled by the load duration curve (LDC).

\section{RELIABILITY INDICES}

In characterizing system elements, generating units and transmission lines, a two state model is used, down and up [1]. For a system composed of E elements, The system will have $2^{\mathrm{E}}$ different capacity states $\mathrm{X}_{\mathrm{i}}, \mathrm{i}=1,2, \ldots 2^{\mathrm{E}}$. The probability that the system will reside in any state is [7].

$F\left(x_{i}\right)=\prod_{m=1}^{E} f\left(Y_{m}\right)$

Where:

$\mathrm{f}\left(\mathrm{Y}_{\mathrm{m}}\right)=\mathrm{p}$, if element $\mathrm{m}$ is available $f\left(Y_{m}\right)=q$, if element $m$ is not unavailable

Moreover, the failed capacity states are capacity states $\mathrm{X}_{\mathrm{i}}$ for which the load cannot be satisfied, either because of insufficient generation capacity or because of insufficient transmission capacity. The system Loss of Load Probability (LOLP) and Loss of Load Expectation LOLE are defined for each of the system operation state $\mathrm{j}$ as:

$$
\begin{aligned}
& \text { LOLP }=\sum f\left(x_{i}\right) \\
& \text { LOLE }=\sum f\left(x_{i}\right) . T
\end{aligned}
$$

$\mathrm{T}$ is the time in days or hours during which the load demand exceeds the remaining generation capacity. In the same vein, LSDi, which is the amount of the load not served at the failure state $\mathrm{i}$, and then the Demand Not Served; DNS; is:

$$
\text { DNS }=\sum \mathrm{f}\left(\mathrm{x}_{\mathrm{i}}\right) \operatorname{LSD}_{\mathrm{i}}
$$

The Expected Energy Not Served (EENS) at the system is defined as:

$$
\mathrm{EENS}=\sum \mathrm{DNS}_{\mathrm{n}, \mathrm{i}} \cdot \mathrm{T}
$$

Where:

DNS $_{\mathrm{i}:} \quad$ :The demand not served at failure state $\mathrm{i}$

n $\quad$ : LDC step number .

$\mathrm{T} \quad$ :The time interval .

\section{APPLICATION OF THE PROPOSED APPROACH TO THE UNIFIED POWER SYSTEM OF EGYPT}

The methodology introduced in this paper has been applied to the Unified Power System of Egypt to evaluate the effect of introducing large wind farms on the system dynamics. The total installed capacity of the Egyptian Power System is $20452 \mathrm{MW}$ in year 2005/06, producing 76297GWh of net generation. About $14 \%$ of the system installed capacity is hydro. Steam turbines installed capacity is the highest share among the other types of the thermal units, it is about $57 \%$ of the system's capacity, while the combined cycle capacity is about $17 \%$. The lowest share is the gas turbines, which is about $12 \%$. The largest unit size in the system is $750 \mathrm{MW}$, while the smallest unit size is $15 \mathrm{MW}$. The system peak load is $17300 \mathrm{MW}$. 
The transmission system is composed of $2262 \mathrm{~km}$ of 500 $\mathrm{kV}$ transmission lines, $14263 \mathrm{~km}$ of $220 \mathrm{kV}$ transmission lines and $2467 \mathrm{~km}$ of $132 \mathrm{kV}$ transmission lines [8].

\section{Dynamic model of conventional generating units Generator model}

Two types of generators are modeled, salient pole and solid rotor generators. Salient pole is presenting hydro power plant generators (High Dam, Aswan Dam, Isna), while the solid rotor generator presenting all other generators of thermal units. In the dynamic simulation, all generator models are presented by Norton equivalent circuit, in which the generator presented by current source. The magnitude and phase of the source current are determined at any instant as a function of the instantaneous values of generator state variables, that is, of rotor circuit flux linkages, shaft speed and rotor angle.

\section{Turbine model}

Three different models describing steam power plan, combined cycle power plant and single shaft gas turbine are modeled.

Steam power plant turbine and boiler: The model is presenting the boiler and steam turbine. The boiler section of the model represents the dependence of drum pressure and throttle pressure on steam flow to the turbine, fuel flow and energy stored in the drum.

Combined cycle plant turbine model: This model is representation of controls associated with the heat recover steam generator boilers and steam turbine in a combined cycle power plant. The gas turbine is connected to this model by external bus of respective gas turbine assuming all gas turbines connected are identical.

\section{Governor model}

Steam turbine governor is a basic model of a speed governor; the shaft speed is the input to the model, while the output is the turbine power (MW).

Hydro turbine governor input data is the shaft speed while the turbine gate position in (pu) and turbine power in (MW) are the model output.

\section{Exciter model}

The exciter control system is modeled by standard IEEE excitation system

\section{RESULTS}

\section{Wind speed versus power generation}

Analyzing the wind regime at the selected site shows that the months of May, Jun, July, August and September are the months of highest mean wind speed. The Egyptian systems experience a high demand at month of June during the year 2005/06. Figure (4) shows monthly average wind speed, while figure (5) shows the expected output power from a wind farm of 900MW versus the expected wind speed for month of June. The wind farm contribute by about $4 \%$ of system peak..

\section{Analysis of wind turbine aggregated model}

The wind farm was aggregated to form three groups of different characteristics, each group is connected to the grid through a step up transformer of 22/220 KV. Table (1) below shows individual turbine characteristics and group characteristics for one of the three wind Farm groups with a capacity of 600 and 900MW.

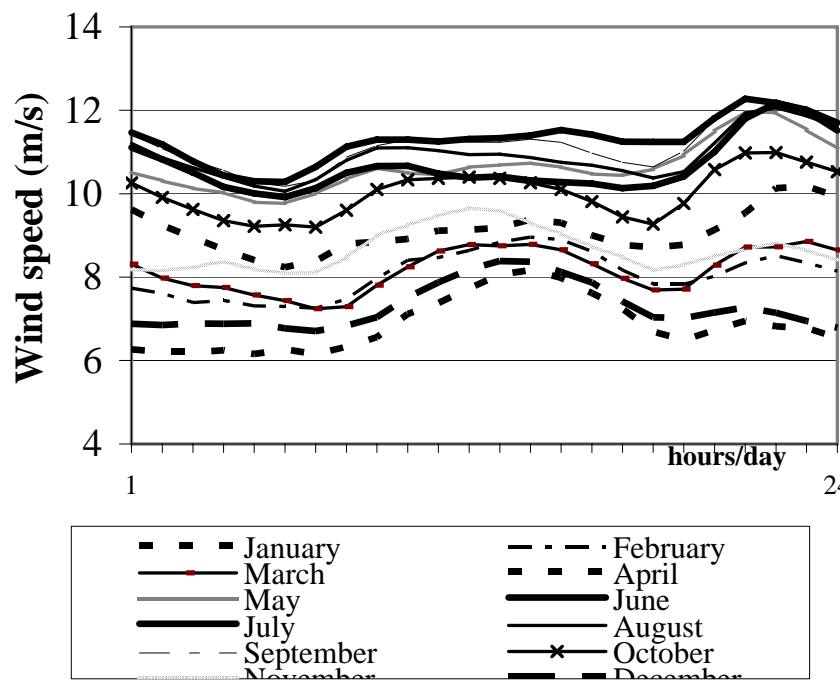

Fig. (4) Wind regime at Zafrana- Gulf of Suez

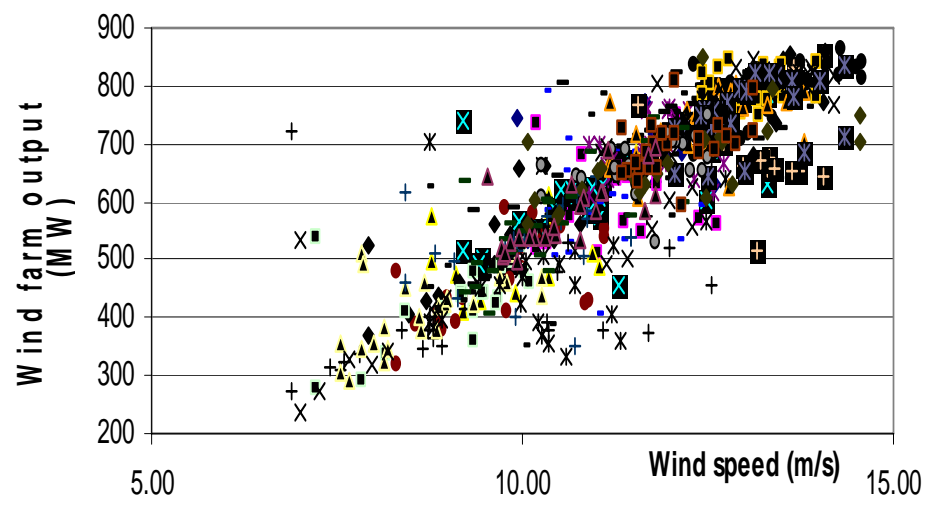

Fig. (5) Expected output from the wind farm of 900MW versus the expected wind speed at month of June

An AC load flow/dynamic behavior simulation was used to conduct the adequacy study of the composite power system. Table (2) shows the wind farm size and the size of conventional unit(s) that replaced by the farm to insure that the system maintains its reliability indices (LOLE and EENS) as before introducing wind farm(s). The reserve requirement in case of introducing 600MW WTGs is the same as before adding it, while it increased by $1.5 \%$ in case of introducing 900MW WTGs. 


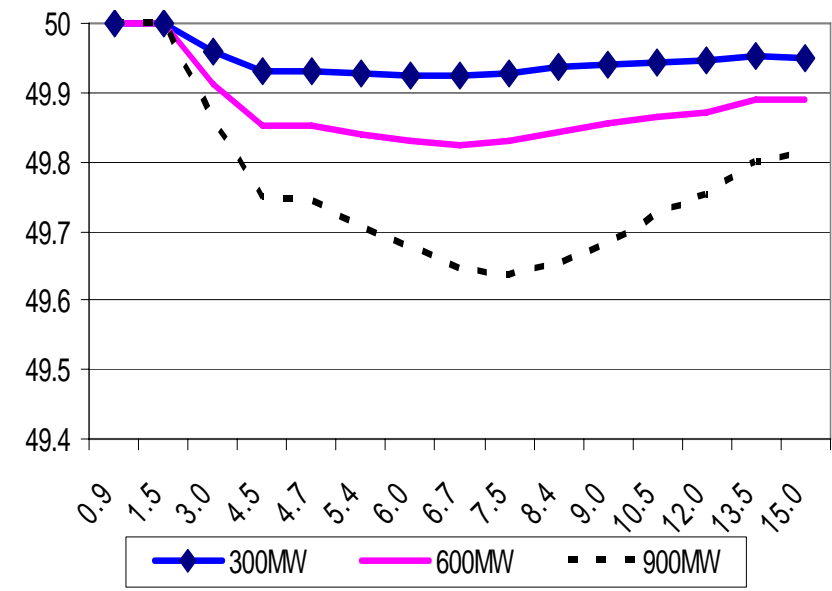

Fig. (6) System frequency response to outage of wind farms of different sizes

Table (1)

Example of WTG characteristics for single turbine and aggregated turbines in p.u

\begin{tabular}{|l|c|c|c|}
\hline \multicolumn{1}{|c|}{ ITEM } & $\begin{array}{c}\text { WTG } \\
\text { of 0.6 } \\
\text { MW }\end{array}$ & $\begin{array}{c}\text { Group of } \\
\text { WTGs } \\
\text { of 200MW }\end{array}$ & $\begin{array}{c}\text { Group of } \\
\text { WTGs of } \\
\text { 300MW }\end{array}$ \\
\hline $\begin{array}{l}\text { Synchronous } \\
\text { reactance,pu }\end{array}$ & 0.004930 & 0.0073562 & 0.0073540 \\
\hline $\begin{array}{l}\text { Transient } \\
\text { reactance,pu }\end{array}$ & 0.000378 & 0.0005624 & 0.0005667 \\
\hline $\begin{array}{l}\text { Stator resistance, } \\
\text { pu }\end{array}$ & 0.000007 & 0.0000104 & 0.0000104 \\
\hline $\begin{array}{l}\text { Transient rotor } \\
\text { time constant,sec }\end{array}$ & 2.623 & 0.188 & 0.187 \\
\hline Inertia constant & 3 & 3 & 3 \\
\hline $\begin{array}{l}\text { Sub transient } \\
\text { reactance,pu }\end{array}$ & 0.000378 & 0.0005624 & 0.0005667 \\
\hline $\begin{array}{l}\text { Stator leakage } \\
\text { reactance, pu }\end{array}$ & 0.000007 & 0.0000104 & 0.0000104 \\
\hline
\end{tabular}

Table (2) Capacity of conventional unit(s) that replaced by the WTGs

\begin{tabular}{|c|c|}
\hline $\begin{array}{c}\text { WTGs Capacity } \\
\text { (MW) }\end{array}$ & $\begin{array}{c}\text { Conventional unit Capacity } \\
\text { (MW) }\end{array}$ \\
\hline 300 & 150 \\
\hline 600 & 260 \\
\hline 900 & 347 \\
\hline
\end{tabular}

Time simulation of system behavior

The outage effect of 300, 600 and 900MW wind farm(s) on the system frequency is shown in figure (6), meanwhile the outage effect of 300,600 and 900 MW of steam power

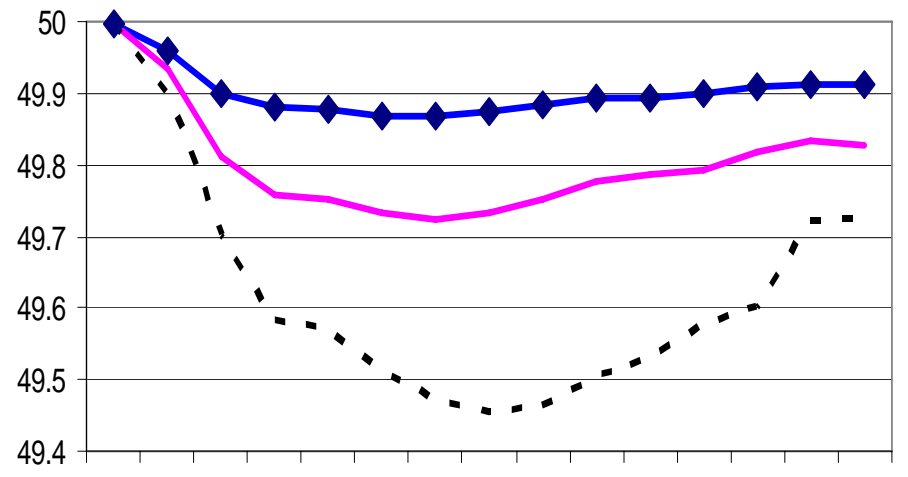

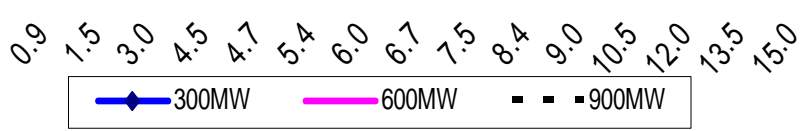

Fig. (7) System frequency response to outage of conventional unit(s) of different sizes

plant(s) on the system frequency before introducing WTGs is shown in figure (7). The results show the outage effect of the wind farm(s) on the system frequency is less than that of thermal units outage of the same size. In both cases the system can withstand the outages without load shedding and can pickup the frequency within 6 seconds.

\section{CONCLUSION}

This paper introduces a technique composed of a deterministic and probabilistic approach to examine WTGs effect on the composite power system performance, due to loss of either large generating unit(s) or load. To investigate the impact of wind farm penetration level power system dynamics should be carried out taking into account the wind speed variation. The group modeling of induction generation is an important issue in the analysis of the dynamic behavior of electric power systems. Instead of developing a detailed model of a wind farm with hundreds of wind turbines and their interconnections an aggregated wind farm model are proposed for system dynamic analysis.

The criteria for selection of the conventional unit(s) that replaced by WTGs wind farm is maintaining the system EENS before and after introducing the wind farm to the system.

\section{REFRENCES}

[1] Mohamed El-Sayed, Mohamed S. Elsobki and Effat Moussa "Wind energy impact on the reliability of composite power system in restructured electricity market" ( CIGRE 2004, France).

[2] Mohamed El-Sayed, Mohamed S. Elsobki , Fouad Taher and Effat Moussa "Economic evaluation of wind energy impact in the Egyptian power system" ( CIGRE 2006, France).

[3] Daniel J. Trudnowski, Andrew Gentile, Jawad M. Khan and M.Petritz "Fixed speed wind generator and wind park 
modeling for transient stability studies” IEEE Transaction on Power Systems Vol. 19, No. 4 November 2004.

[4] D.C. Franklin and A.Marelato "Improving dynamic aggregation of induction models" IEEE Transactions on Power Systems, Vol. 9 No.4, November 1994.

[5] J.Khan "Modeling a wind generator farm for transient stability using equivalencing" M.S. thesis, Montana Tech, Univ. of Montana, Butte, MT.2003.
[6] Olle l.Elgard "Electric Energy System Theory" TATA McGraw-Hill Publishing company LTD,1983.

[7] R.L.Sulivan “power system Planning” McGraw-Hill, 9. Inc.1977.

[8]Annual Report for year 2005/2006, Egyptian Electricity Holding Company. 